\title{
A DIFICULDADE NA LEITURA DE O CAPITAL DE MARX: A POSIÇÃO ALTHUSSERIANA
}

Fernando Bonadia de Oliveira*

Resumo: As dificuldades que envolvem a leitura e compreensão de O Capital de Karl Marx são consideradas por Louis Althusser em seu prefácio à edição francesa desta obra. Este artigo tem como objetivo investigar o problema da dificuldade na leitura do livro de Marx, a partir de uma análise da recomendação althusseriana, segundo a qual se deve iniciar a leitura de $O$ Capital deixando de lado, a princípio, sua seção primeira. Posteriormente, será mostrado como o próprio filósofo alemão aborda as dificuldades de compreensão de sua obra e de que forma é possível rever a recomendação do filósofo contemporâneo francês.

Palavras-chave: Louis Althusser, Karl Marx, O Capital (1867), abstração, dialética.

\section{Introdução}

O Capital de Karl Marx, obra inicialmente projetada para ser composta em quatro livros, teve seu primeiro volume publicado no ano de 1867. Esta primeira parte, que trata do processo de produção do capital, resume, em seu capítulo 1, conforme salienta o próprio autor no "Prefácio" da primeira edição, a Contribuição à Crítica da Economia Política, lançada em 1859.

Esta obra, um dos pontos mais elevados da filosofia moderna e contemporânea, apresenta uma profunda e rigorosa crítica à chamada

* Doutorando em Filosofia pela Universidade de São Paulo 
economia política burguesa, desenvolvida no século XIX. Composta a partir de um método dialético de construção que requer detalhada reflexão e aprendizagem filosófica, ela teve ampla recepção, assumindo até a atualidade o caráter indubitável de um texto clássico ${ }^{2}$.

Segundo o parecer de Ítalo Calvino,

Os clássicos são aqueles livros que chegam até nós trazendo consigo as marcas das leituras que precederam a nossa e atrás de si os traços que deixaram na cultura ou nas culturas que atravessaram (ou mais simplesmente na linguagem ou nos costumes) (Calvino 7, p. 11).

Este livro de Marx, em virtude de suas importantes conseqüências históricas e de sua ampla capacidade de explicação da realidade, tornouse um clássico que mereceu sempre novas leituras. A obra recebeu, desde sua publicação, um grande número de tentativas de aproximação por parte de historiadores, economistas, pedagogos e cientistas sociais. Não raro, porém, a primeira leitura desta obra é qualificada como difícil e o próprio Marx, como será evidenciado adiante, assume sua dificuldade.

Alguns comentadores de Marx centram a dificuldade da leitura de $O$ Capital na consistência do seu "modo de exposição" dialético e fenomenológico, que parte do "aparentemente verdadeiro" ou "geralmente aceito"’ para só depois efetuar sua negação, criando uma análise dinâmica, pautada em um movimento que deve ser acompanhado até o final ${ }^{4}$. Para outros estudiosos do marxismo, a dificuldade principal na leitura desta obra reside na ação de abstrair, frequentemente solicitada por Marx para a compreensão mais perfeita de seus conceitos e raciocínios.

Louis Althusser dedicou-se a atenuar o grau da dificuldade do primeiro contato de um leitor com O Capital (Marx 8), elaborando, em seu prefácio à edição francesa da obra (assinado em março de 1969)5 , uma espécie de guia por meio do qual os principais ardis para o entendimento do livro pudessem ser mais suavemente superados.

Este artigo tem como finalidade explicar qual é a compreensão althusseriana dessa dificuldade e, em seguida, analisar a forma pela qual o próprio Marx considera os obstáculos de seu livro, de modo que, a título de conclusão, seja permitido rever a posição de Althusser segundo a qual é recomendável ao leitor leigo iniciar sua leitura da obra saltando a seção inicial do livro I.

\section{As dificuldades de leitura de $O$ Capital segundo Althusser}

Os problemas relativos a $O$ Capital animaram continuamente a produção de Althusser, que chegou a escrever (em colaboração com outros teóricos) um livro intitulado Lire Le Capital (1965), além de inúmeros opúsculos que tocam, de alguma maneira, o pensamento econômico marxista. Leitor atento do texto de Marx, Althusser oferece àquele que se aproxima da famosa obra marxiana um conjunto de esclarecimentos, indicações e recomendações de leitura.

Segundo seu prefácio à edição francesa, há um paradoxo inerente à leitura de $O$ Capital: esta obra, apesar de suas dificuldades, é mais incompreendida por especialistas e intelectuais do que por militantes do movimento operário e trabalhadores assalariados. A razão da maior facilidade de leitura por parte do proletariado se deve, para ele, à proximidade que esta classe tem do objeto de estudo de Marx, qual seja, a exploração promovida pelo sistema capitalista. O motivo da dificuldade mais acentuada sentida pelos especialistas e intelectuais é, por sua vez, sua submissão à ideologia capitalista, que, repetidas vezes, os impede de ter "condições de criticar eles mesmos as ilusões em que vivem e que contribuem para manter" (Althusser 3, p. 8). 
A leitura de $O$ Capital possui, no entender de Althusser, dois gêneros de dificuldades: a primeira é uma dificuldade ideológica e política; a segunda é uma dificuldade teórica ${ }^{6}$.

Quanto ao primeiro gênero de dificuldade, os leitores que têm experiência direta com a exploração capitalista (sobretudo os proletários urbanos e rurais) não sofrem com a leitura da obra, uma vez que Marx trata, em suas páginas, de sua vida concreta. Os leitores que não têm experiência direta com a exploração engendrada pelo capital e que mantêm em suas mentes a ideologia dominante, ao contrário, sofrem com isso: há uma "incompatibilidade política entre o conteúdo teórico de $O$ Capital e as idéias que têm na cabeça" (Althusser 3, p. 9).

Quanto ao segundo tipo de dificuldade, a teórica, Althusser afirma que os leitores habituados ao pensamento teórico (os intelectuais), deveriam experimentar menos dificuldades com esta leitura. Ao contrário, os que menos possuem cultura teórica (os operários) deveriam enfrentar maiores problemas em sua compreensão. No entanto, isso não ocorre efetivamente: “(...) até indivíduos sem prática nos textos teóricos (como os operários) experimentaram menos dificuldade ante $O$ Capital que os indivíduos doutos em prática de teoria pura (como os sábios ou falsos sábios muito 'cultivados')" (Althusser 3, p. 9).

Em torno desta questão, o pensador francês assegura aos futuros leitores da obra que as dificuldades políticas e ideológicas são as mais determinantes para a leitura.

Tratando a dimensão teórica do problema, Althusser destaca a questão da abstração. A prática da abstração é, para ele, uma "verdadeira aprendizagem" (Althusser 3, p. 10) e, conforme afirma o próprio Marx, é um instrumento para o conhecimento filosófico, assim como o microscópio é uma ferramenta fundamental para a Biologia?.
A certa altura de seu comentário, Althusser afirma que, resumidamente, $O$ Capital apresenta apenas uma dificuldade, que é teórica. Trata-se, de acordo com ele, de uma dificuldade real e objetiva, apenas superável através de uma aprendizagem da abstração, o que não se alcança apenas em um dia (Althusser 3, p. 12).

A fim de superar os problemas que emergem no momento em que o leitor abre essa obra para uma primeira aproximação, Althusser indica três conselhos, a saber, (1) compreender que esta é uma obra de teoria que tem como objeto os mecanismos do modo de produção capitalista; (2) não almejar encontrar naquelas páginas um livro de história ou de economia política, mas uma obra teórica que cuida de examinar o modo de produção capitalista e (3) tomar as medidas necessárias para reverter as dificuldades teóricas cada vez que elas se apresentarem ${ }^{8}$.

A análise de tais dificuldades é dividida por Althusser em dois pontos: o primeiro contém conselhos de leitura com a finalidade de evitar os obstáculos de entendimento e o segundo dispõe indicações sobre as dificuldades teóricas do livro I de $O$ Capital.

Acerca do primeiro ponto, o comentador de Marx aconselha que a primeira leitura do livro coloque entre parêntesis toda a seção I (sobre mercadoria e dinheiro), iniciando-a pela seção II (sobre a transformação do dinheiro em capital) ${ }^{9}$. Posteriormente, é recomendado ler as seções III (a produção da mais-valia absoluta), IV (a produção da mais-valia relativa) e abandonar a seção V (que contém novas investigações sobre a mais-valia). Em seguida, Althusser indica que se leia com atenção as seções VI (sobre o salário), VII (sobre a acumulação do capital) e VIII (sobre a acumulação originária). Finalmente, defende que o leitor inexperiente em $O$ Capital comece - com numerosas precauções - a leitura da seção I, sabendo que ela será muito difícil de compreender. 
A respeito do segundo ponto, Althusser afirma que há duas ordens de dificuldades. A primeira delas emerge do fato de que o livro I de OCapital deva ser compreendido tendo em vista que há outros três livros que o completam. Embora Engels tenha afirmado que o livro I encerre em si uma unidade, "o conhecimento dos três livros restantes permite resolver certo número de dificuldades teóricas muito graves do livro I, principalmente as que estão concentradas na terrível seção I (a mercadoria e o dinheiro), em torno da famosa teoria do "valor-trabalho"'. A segunda consiste na necessidade de se "ler O Capital muito de perto". Esta leitura deve ser praticada e exercitada com intensidade, atenção e rigor. (Althusser 3, p. 27).

Para compreender esta obra de Marx, finaliza Althusser, "é necessário 'tomar posições de classe proletária', quer dizer, situar-se no único ponto de vista que torne visível a realidade da exploração da força de trabalho assalariada que realiza todo o capitalismo" (Althusser 3, p. 39).

\section{As dificuldades de $O$ Capital segundo Karl Marx}

O problema da dificuldade foi tratado pelo próprio Karl Marx em seu "Prefácio" para a primeira edição de $O$ Capital. O filósofo alemão começa sua abordagem sobre os ardis de sua obra, afirmando que "todo começo é difícil" e que essa afirmação "vale para qualquer ciência" (MARX 9, p. 129) ${ }^{10}$.

Nas palavras do autor,

O entendimento do capítulo I, em especial a parte que contém a análise da mercadoria, apresentará, portanto, a dificuldade maior. Quanto ao que se refere mais especificamente às análises da substância do valor e da grandeza do valor, procurei torná-las acessíveis ao máximo. A forma do valor, cuja figura acabada é a forma do dinheiro, é muito simples e vazia de conteúdo. Mesmo assim, o espírito humano tem procurado fundamentá-la em vão há mais de 2000 anos, enquanto, por outro lado, teve êxito, ao menos aproximado, a análise de formas muito mais complicadas e replenas de conteúdo. Por quê? Porque o corpo desenvolvido é mais fácil de estudar do que a célula do corpo (Marx 9, p. 129-130).

Como se depreende do texto transcrito, Marx reconhece a dificuldade das primeiras páginas de sua obra, assegurando que teve o cuidado de tornar o texto sobre a grandeza e a forma do valor o mais acessível a seus leitores.

Detendo-se à questão sobre a forma do valor, o filósofo argumenta que, não obstante a ausência de conteúdo de sua figura mais completa (o dinheiro), houve uma dificuldade histórica em compreendê-la, porque "o corpo desenvolvido é mais fácil de estudar do que a célula do corpo". Com esta sentença, entende-se que a causa da dificuldade de compreensão da primeira seção é o aspecto microscópico do objeto submetido a exame e a ausência de um aparelho que sirva ao filósofo como o microscópio serve ao biólogo e os reagentes ao químico.

Neste caso, como seria possível compensar a falta de um instrumento tão objetivo como o microscópio é para a ciência natural? O próprio Marx responde:

A faculdade de abstrair deve substituir ambos [o microscópio e os reagentes químicos utilizados nas investigações em ciência natural]. Para a sociedade burguesa, a forma celular da economia é a forma de mercadoria do produto do trabalho ou a forma do valor da mercadoria. Para o leigo, a análise parece perder-se em pedantismo. Trata-se, efetivamente, de pedantismo, mas daquele de que se ocupa a anatomia microscópica (Marx 9, p. 130). 
Nesta perspectiva, é a faculdade de abstração (já discutida por neste trabalho através da análise althusseriana) que deve ocupar o lugar do microscópio; será esta técnica ou este método o que proporcionará o entendimento da forma celular da economia em uma sociedade regida pelo modo de produção capitalista. Como em toda análise que se pretende microscópica, no parecer de Marx, cai-se em pedantismo, porém, trata-se de um pedantismo necessário, que deve ser enfrentado para uma compreensão cabal do problema pesquisado. Isso, para o leigo, é um incômodo e um obstáculo, todavia, sua superação é o fundamento da compreensão do problema que ele intenta conhecer.

$\mathrm{O}$ autor de $O$ Capital conclui esta passagem afirmando que, afora a questão sobre a forma do valor, "não se poderá acusar este livro de ser de difícil compreensão". Ele pressupõe, afinal, "leitores que queiram aprender algo de novo e queiram, portanto, também pensar por conta própria" (Marx 9, p. 130).

Com esta alegação, Marx evidencia também o aspecto educativo de sua obra: ela se destina a aprendizes e foi escrita para eles, tendo o autor procurado - como expositor didaticamente precavido - tornar todas as coisas necessariamente difíceis "acessíveis ao máximo". Tal aprendizado tem por objeto, mais do que qualquer outra coisa, a abstração e a o domínio da arte dialética ${ }^{11}$.

\section{Conclusão}

Se forem examinadas atentamente as duas ordens de dificuldade apontadas por Althusser para uma leitura inicial de O Capital (a ordem ideológica/política e a ordem teórica), será certamente fácil concordar com a primeira; entretanto, o mesmo não ocorrerá com as consequências que o filósofo francês extrai de sua consideração a respeito dos embaraços teóricos do livro.
É inegável que a dificuldade ideológica, de cunho político, opera intensamente sobre a primeira aproximação da obra de Marx, afinal, sendo ela extensa e exigindo do leitor alguma familiaridade com o estudo da economia política clássica, a perseverança na leitura até o final é profundamente prejudicada quando se pensa que o assunto é abstrato e quando não se sabe que são tratadas ali, na verdade, coisas muito concretas.

É válido notar que Althusser tem plena razão sob esse aspecto, pois o leitor só sentirá a concreção do tema abordado por Marx quando se desvencilhar da ideologia dominante, isto é, quando - de alguma forma se aproximar do ponto de vista da classe operária.

O próprio livro se incumbe, porém, de provocar no leitor essa adesão à perspectiva proletária, pois à proporção que se lê e relê suas páginas durante alguns dias e se mantém a lida cotidiana, vai-se notando, amiúde, sua materialidade e concretude, seja na hora de entrar em um supermercado ou no momento em que se passa por um corredor de vendedores ambulantes. A riqueza da sociedade capitalista que, antes da primeira passada de olhos pela obra, aparecia de fato como uma "imensa coleção de mercadorias" (tese da economia política burguesa), com os primeiros movimentos de leitura, "se manifesta como imensa coleção de contradições" e a luta de classes se define como sua "contradição fundamental", presente em cada mercadoria (Benoit 5, p. 35).

A transição de um conceito a outro - promovida pelas linhas de $O$ Capital - efetua uma passagem do "instinto de classe burguês" a uma "posição (objetiva) de classe proletária" ${ }^{12}$. Àqueles que não foram determinados a compreender o texto por sua experiência pessoal sob a exploração capitalista diária, a revolução teórica advinda da leitura dessa obra lhes restitui, de alguma forma, a consciência proletária. Do contrário, não teria sido possível a Marx e Engels, como lembra Althusser, elaborar uma teoria revolucionária ${ }^{13}$. 
Se a dificuldade dita ideológica tem suas formas de minimização na própria literalidade do texto de Marx e no conhecimento efetivo do modo de produção capitalista, dispensando qualquer esquema de leitura além daquele que a própria obra apresenta, resta inquirir se o mesmo acontece com a dimensão teórica das dificuldades.

A dificuldade teórica para o bom entendimento de $O$ Capital não se restringe ao problema da abstração, apesar de Althusser se centrar neste ponto. É necessário ler o texto de Marx tendo consciência que seu autor está, a cada passagem, dialogando ou se dirigindo a alguma ou a algumas tradições de pensamento densas e complexas, como a economia política clássica e o hegelianismo. Para bem compreender o trabalho do filósofo alemão, é necessário valer-se de conceitos nem sempre facilmente inteligíveis e de um outro método de raciocínio raramente empregado e experimentado nos tempos atuais: a dialética.

O método (dialético) de $O$ Capital mistura-se profundamente com o modo de exposição escolhido para a obra e, inclusive, com a ordenação precisa de seus capítulos. O próprio Marx manifestou, como já foi evidenciado, sua preocupação com a clareza de suas ideias ${ }^{14}$. Portanto, qualquer alteração no roteiro de leitura da obra - como desejou Althusser, ao sugerir, por exemplo, saltar a seção I - resultaria equivocada, afinal, romper com o modo de exposição do filósofo, impediria a adequação entre o leitor e o movimento dialético do livro.

Consideramos fundamental a defesa da literalidade e o respeito rigoroso do modo de exposição de Marx. Não se trata de uma exigência vinculada a uma defesa incondicional de um suposto "marxismo ortodoxo", ou de uma defesa fetichista do texto de Marx. Esta exigência coloca-se, para nós, pois, a nosso ver, estaria no próprio modo de exposição, na própria disposição das diversas partes da obra $O$ Capital, na literalidade do texto último que Marx nos deixou, particularmente, no primeiro livro de $O$ Capital (o único acabado), estaria ali, nesta literalidade, um conteúdo conceitual fundamental jamais suficientemente compreendido e pensado por grande parte dos próprios marxistas: ali, na própria disposição das partes, estaria a manifestação do pensamento de Marx, enquanto devir, enquanto processo transitório, em uma expressão, enquanto movimento dialético (Benoit 6, p. 82) ${ }^{15}$.

Diante da breve investigação aqui apresentada, conclui-se que o equívoco da posição althusseriana acerca das dificuldades de leitura de $O$ Capital é sua tentativa de facilitar um trabalho de compreensão (teórica) do modo de produção capitalista que, uma vez facilitado, não dá conta da compreensão desejada, por querer evitar o difícil, isto é, o começo. Não só a ordem escolhida por Marx é a mais adequada do ponto de vista teórico, como foi objeto de sua preocupação expor seu pensamento de maneira clara. A dificuldade surge da complexidade do próprio objeto (como aponta o autor), mas recusar o seu enfrentamento consiste justamente em não compreender a obra ou então, em compreendê-la numa ordem indevida.

Experimentar uma primeira leitura de $O$ Capital dentro da ordem proposta por Althusser, a saber, aquela que principia pela seção II, deve, sem dúvida, tornar menos ardiloso o contato da segunda leitura. No entanto, quando se parte da certeza de que é impossível, de fato, compreender todo o livro na primeira lida, nada parece mais razoável do que realizar a primeira leitura já na ordem planejada pelo autor, isto é, partindo da seção I do Livro I, com a confiança de que, na segunda leitura, o processo de abstração já será mais comum e palatável ao leitor, uma vez que ele já estará acostumado com o método. 
Neste caso, o clássico é aquele livro que os homens sempre lêem pela segunda vez". É impossível, portanto, uma leitura "mais de perto" de $O$ Capital, como recomenda Althusser, sem que esta seja sempre uma nova leitura.

\section{THE MAIN ISSUES ON THE READING OF MARX'S CAPITAL: THE ALTHUSSERIAN PERSPECTIVE}

Abstract: The difficulties related to the reading and comprehension of Karl Marx's Capital are considered by Louis Althusser in its preface to the French edition of the book. The goal of this article is to investigate the difficulties on its reading, starting by the analysis of Althusser's recommendation, in which on one should begin the reading of Capital by skipping the first section. Thereafter, it will be shown how Marx himself approaches the comprehension issues of his work and how it is possible to review the suggestion of the contemporary French philosopher.

Keywords: Louis Althusser, Karl Marx , Capital (1867), abstraction, dialectics.

\section{REFERÊNCIAS BIBLIOGRÁFICAS}

1.ALTHUSSER, L. Advertencia a los lectores del libro I de El Capital. In: Escritos. Barcelona: Laia, 1975. Traducción: Albert Roies Qui.

2. Comment lire Le Capital. In: Positions (1965-1975). Paris: Sociales, 1976

3. Gu Guía para leer el Capital. Revista de Filosofia y Teoria Social. Buenos Aires, ano 1, nº 2, 1992. Tradução: Dario Diaz.

4. ARISTÓTELES. Tópicos. In: Os Pensadores. São Paulo: Abril Cultural, 1973. Tradução: Leonel Vallandro \& Gerd Bornheim.

5. BENOIT, H. Sobre a crítica (dialética) de O Capital. Revista Crítica Marxista. São Paulo, no. 3, 1993, p. 14-43.

6. Pensando com (ou contra) Marx? Sobre o método dialético de O Capital. Revista Crítica Marxista. São Paulo, nº. 8, 1999, p. 81-92.

7. CALVINO, I. Por que ler os clássicos? São Paulo: Companhia das letras. 1993.

8. MARX, K. Le Capital. Paris: Garnier-Flammarion, 1969.
9. O Capital. Livro I. São Paulo: Nova Cultural, 1996. Tradução: Regis Barbosa \& Flávio Kothe. (Col. Os Economistas).

10.PLATÃO. Político. In: Os Pensadores. São Paulo: Abril, 1983. Tradução: Jorge Paleikat e João Costa.

\section{NOTAS}

2. A crise econômica global de 2008 gerou na Alemanha um grande aumento das vendas de $O$ capital. Além disso, nos três últimos anos foram produzidas, em função das sucessivas crises, recriações dessa obra no cinema (Histórias da Antiguidade Ideológica, de Alexandre Kluge, 2009) e até mesmo em versão mangá, lançada no Japão em 2008 e traduzida recentemente para a língua portuguesa pela editora JBC.

3. Convém mencionar qual é a posição de Aristóteles, nos Tópicos, acerca deste traço definidor da dialética: "o raciocínio é dialético quando parte de opiniões geralmente aceitas (...). São (...) 'geralmente aceitas' aquelas que todo mundo admite, ou a maioria das pessoas, ou os filósofos - em outras palavras: todos, a maioria, ou os mais notáveis e eminentes" (Aristóteles 4, 100b 18-22).

4. Não é incomum encontrar citações fragmentadas de Marx que, equivocadamente, expõem como posição do autor aquilo que ele apenas admite previamente para depois refutar.

5. Há edições castelhanas deste texto sob o título "Advertência a los lectores del libro I de El Capital" (ver Althusser 1, 3). Foi publicada também em Positions (1964-1975) uma súmula das principais ideias deste texto (Althusser, 2).

6. Em Positions (1964-1975), o pensador francês qualifica expressamente a primeira dificuldade como "determinante" e a segunda como "subordinada" (Althusser 2, p. 50).

7. A esta altura, o autor de Lire le Capital faz um importante registro sobre o problema da abstração. Esta espécie de abstração sustentada por Marx não é "abstrata" no sentido que o senso comum confere a esta palavra: “(...) conceito abstrato quer dizer, então, fórmula aparentemente abstrata, mas, na realidade, terrivelmente concreta, por causa do objeto que designa" (Althusser 3, p. 11). Para ele, os conceitos marxistas apresentados em $O$ Capital, são mais concretos do que as coisas que todos podem tocar com as mãos, embora não seja possível toca-los. Assim se passaria com os conceitos de "valor de troca", "capital social total" e "trabalho social necessário".

8. O leitor não deve se apressar em ler a obra, mas voltar a leitura, com vagar, avançando quando estiver esclarecido de suas dúvidas (Althusser 3, p. 13). 
9. Para ele, esta seção II contém o coração de $O$ Capital, isto é, a teoria da mais-valia. 10.Althusser comenta essa afirmação de Marx da seguinte forma: "Dentro de uma concepção hegeliana da ciência (para Hegel há ciência só se esta é filosófica e é por isso que toda verdadeira ciência deve fundar seu próprio começo), Marx pensava, então, que 'em toda ciência, o começo é árduo"” (Althusser 3, p. 27).

11. Conforme afirmara Estrangeiro ao jovem Sócrates no Político (Platão 10), a finalidade de todo diálogo - para além de seus objetivos específicos - é tornar os interlocutores "melhores dialéticos a respeito de qualquer assunto" (284a). Estes aprendizes pressupostos por Marx são, como este mesmo filósofo defendeu, os que querem aprender o novo e a pensar por si mesmos.

12.Vale lembrar que Althusser distingue três situações: o "instinto de classe burguês", o "instinto de classe proletária" e a "posição (objetiva) de classe proletária". Somente esta última, em seu parecer, é plenamente adequada. O Capital auxilia os operários fornecendo-lhes "educação teórica sob a forma de explicações e demonstrações objetivas" (Althusser 3, p. 40).

13. "O próprio Marx [era] filho de burguês liberal (advogado) e Engels da alta burguesia capitalista e, durante vinte anos, ele mesmo [era] capitalista em Manchester. Toda a história intelectual de Marx pode e deve se compreender assim: uma larga, difícil e dolorosa ruptura (...) que [ele] ajudou a definir de maneira decisiva em $O$ Capital" (Althusser 3, p. 40).

14. Vale lembrar a afirmação de Marx: "as análises da substância do valor e da grandeza do valor, procurei torná-las acessíveis ao máximo" (Marx 9, p. 129)

15. O autor aprofunda ainda mais a crítica aos que pretendem facilitar $O$ Capital: "Pensam (...) que podem ser mais didáticos que Marx (...) ou que podem melhorar ou ainda aperfeiçoar o pensamento de Marx alterando a ordem de Marx, recortando seu texto, tirando pedaços, juntando e sobrepondo outros textos (às vezes, esboços do próprio Marx, manuscritos não publicados, etc.). Ora, se esquecem que Marx gastou anos e anos lutando para encontrar a unidade dialética entre forma e conteúdo, ou para usar as palavras do próprio Marx, se esquecem que ele gastou muito tempo para encontrar 'a vida da matéria' (...), a disposição correta das partes, disposição esta que constitui a superação do momento" (Benoit 6, p. 82).

16. Nas palavras de Ítalo Calvino, "os clássicos são aqueles livros dos quais, em geral, se ouve dizer: ‘Estou relendo...' e nunca ‘Estou lendo...”' (Calvino 7, p. 9).

\section{MAQUIAVEL, OU O MAIS LONGO DESVIO: ACONTECIMENTO, ENCONTRO E MATERIALISMO NA FILOSOFIA DO ÚLTIMO ALTHUSSER}

Pablo Azevedo*

Resumo: O presente texto pretende esboçar a leitura de uma teoria do acontecimento no "último Althusser", a partir de dois textos de capital importância no conjunto de sua obra póstuma: Machiavel et nous (1972-1986) e Le courant souterrain du matérialisme de la rencontre (1982). No primeiro texto, Althusser busca através da análise do pensamento do secretário florentino refletir uma teoria da práxis da transformação política; enquanto no segundo ensaio, procura empreender a tarefa de construir genealogicamente uma corrente materialista onde o primado ontológico do encontro substitua a teleologia do materialismo dialético. A partir destes pontos, gostaríamos de buscar uma leitura compositiva dos dois textos, no sentido de percebermos se é possível ler na ontologia althusseriana do materialismo do encontro e em sua interpretação de Maquiavel uma teoria do acontecimento.

Palavras-Chave: Althusser, Acontecimento, Encontro, Maquiavel, Materialismo

Chove. É com esse simples enunciado que Althusser inicia seu texto Le courant souterrain du matérialisme de la rencontre (1982), inicialmente afirmando discorrer sobre a simplicidade de um evento corriqueiro, o ato de chover. Ação impessoal, sem um "sujeito" providencial ou contraprovidencial que execute tal ação (na verdade, isso pouco importa), a chuva emerge na estrutura do texto para além de sua dimensão

* Doutorando em Filosofia UFRJ. 